
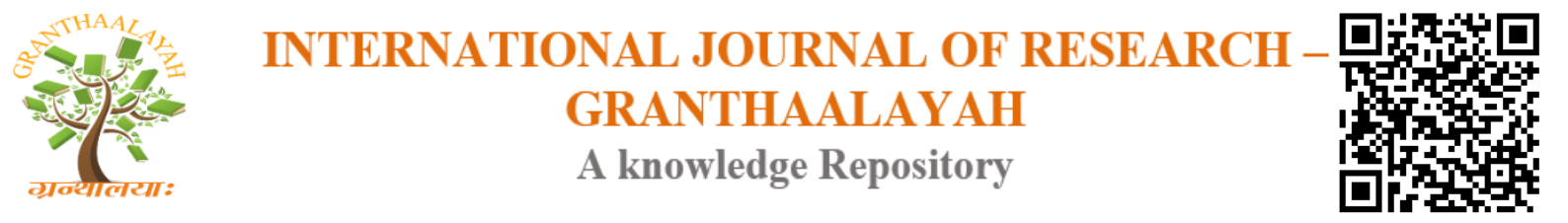

Science

\title{
AERVA LANATA LEAF EXTRACT AS A CORROSION INHIBITOR FOR CARBON STEEL IN CHLORIDE ENVIRONMENT
}

\author{
V. Rajesh *1, E. U. B. Reddi ${ }^{2}$, T. Byragi Reddy ${ }^{2}$, Ch. Durga Prasad ${ }^{2}$, B. Prasanna Kumar ${ }^{2}$ \\ ${ }^{* 1}$ Department of Chemistry, V. R. Siddhartha Engineering College (Autonomous), Vijayawada- \\ 520007, Andhra Pradesh, India \\ ${ }^{2}$ Department of Environmental Sciences, College of Science and Technology, Andhra \\ University, Visakhapatnam-530003, Andhra Pradesh, India
}

\begin{abstract}
The present study was initiated with an objective of investigating a plant extract as an effective corrosion inhibitor useful for protection of carbon steel in aqueous environment containing chloride ions. For this purpose, the leaf extract of the plant 'Aerva lanata' belonging to Amaranthaceae family of genus Aerva was chosen. The required optimum concentration of the extract for an effective inhibition was found to be $5 \%$, resulting in the inhibition efficiency of 95 $\%$ against corrosion of carbon steel in $200 \mathrm{ppm}$ of $\mathrm{NaCl}$ solution. The extract introduced as a corrosion inhibitor was found to be effective in the $\mathrm{pH}$ range from 4.0 to 9.0. The extract could retain its inhibition efficiency for about an immersion period of 60 days and also up to a temperature of $333 \mathrm{~K}$. The $5 \%$ extract was found to control corrosion of carbon steel in highly aggressive medium containing $300 \mathrm{ppm}$ of $\mathrm{NaCl}$ also. In order to maintain the protective nature, the required concentration of the extract was $2 \%$. From these studies, it was inferred that the Aerva lanata leaf extract exhibits good inhibitive properties for carbon steel in aqueous environment in wide ranges of $\mathrm{pH}$, temperature and aggressiveness of medium.
\end{abstract}

Keywords: Corrosion Inhibitor; Aerva Lanata; Gravimetric Measurements; Leaf Extract; Environmental Factors; Carbon Steel.

Cite This Article: V. Rajesh, E. U. B. Reddi, T. Byragi Reddy, Ch. Durga Prasad, and B. Prasanna Kumar. (2018). "AERVA LANATA LEAF EXTRACT AS A CORROSION INHIBITOR FOR CARBON STEEL IN CHLORIDE ENVIRONMENT." International Journal of Research - Granthaalayah, 6(11), 153-162. https://doi.org/10.29121/granthaalayah.v6.i11.2018.1084.

\section{Introduction}

It is well-known that corrosion has been a very serious concern regarding the structures of metals and alloys. Researchers working in the field of corrosion have been striving for protecting metallic structures from corrosion by applying a variety of possible protection methods. Application of corrosion inhibitors is one of the effective and economical methods of corrosion control. Numerous reports on various organic and inorganic compounds as effective corrosion inhibitors 
can be observed in literature. A major disadvantage with some of these inhibitors is that they increase environmental toxicity. In order to address this challenge, a lot of work has been in progress since past three decades in the direction to i) decrease toxicity of the inhibitor formulations and ii) develop non-toxic and natural corrosion inhibitors.

There are some reports in literature that show the reduction of toxicity of the inhibitor formulations. For instance, Sarada Kalyani et al. (2015) reported their studies on corrosion inhibition of carbon steel using nitrilotris (methylenephosphonic acid), zinc ions and nicotinic acid. They reported that concentration of zinc ions required for effective inhibition could be reduced by the addition of nicotinic acid which is a non-toxic compound. In another study by Srinivasa Rao et al. (2014), relatively low-toxic ternary inhibitor formulation containing phosphonobutane-1,2,4-tricarboxylic acid, zinc ions and lactobionic acid was reported. According to this report, the required concentrations of both phosphonate and zinc ions for effective corrosion inhibition are low in presence of the non-toxic additive lactobionic acid. There are some more reports in literature pertaining to decrease zinc ion toxicity by the addition of environment friendly compounds as synergists, reported by Sarada Kalyani et al. (2017), Appa Rao et al. (2011) and Appa Rao et al. (2010). Addressing the same challenge, a large number of natural plant extracts were also studied for their corrosion inhibitive effect. Leaf extracts are one among the effective inhibitors along with the extracts obtained from other parts of plants like roots, stem, seeds, fruits and flowers.

There are some recent reports on inhibition of corrosion of carbon steel using leaf extracts. Khadom et al. (2018) reported their studies on corrosion inhibition of low carbon steel using Xanthium strumarium leaves extracts in $1 \mathrm{M}$ hydrochloric acid solution. Muthukrishnan et al. (2017) in their report on corrosion inhibiting action of Lannea coromandelica leaf extract on mild steel inferred that the extract works as an effective corrosion inhibitor in $1 \mathrm{M}$ sulphuric acid solution by following adsorption mechanism. It was reported that the extract acted as a mixed type inhibitor and obeyed Langmuir adsorption isotherm. Hamdan et al. (2018) studied corrosion inhibition of mild steel in hydrochloric acid solution using tea leaves extract. They found that the rate of corrosion of the metal decreased with increase in concentration of the extract. Cookey et al. (2018) reported that leaves extract of Clivia nobilis, also known as green-tip forest lily, can control corrosion of mild steel in both hydrochloric acid and sulphuric acid environments. Chandrabhan Verma et al. (2018) reported their study on corrosion inhibition of mild steel in acidic environment containing Holoptelea integrifolia leaf extract. Based on weight-loss method, surface analytical methods, electrochemical methods and density functional theory method, they inferred that the extract acts as a mixed type inhibitor and protects the metal through adsorption at the metal/solution interface. In another study by Michael and Olubunmi (2014), the authors reported that flavonoid (catechin) separated from Nypa fruticans Wurmb leaves extract can control corrosion of mild steel in sulphuric acid solution. It was reported that Acanthus montanus extract from its leaves, stem and roots, acts as an effective corrosion inhibitor for mild steel in acidic medium (Ibisi and Ufodiama, 2016). Shanmuga Priya and Vasudha (2015) studied inhibiting action of acid extract of leaves of Polyalthia Longifolia for mild steel in sulphuric acid solution and based on the results, they inferred that the extract acts as a good corrosion inhibitor with an efficiency of $92 \%$ at the extract concentration of $1.5 \%$. In one of the recent studies, Akoma Chigozie et al. (2018) studied inhibitive action of Chrysophyllum albidum extract on corrosion of mild steel immersed in some carbonated drinks. All the above reports are found to conclude that the leaf extracts of various plants can act as effective inhibitors for corrosion of carbon steel in 
acidic environments. There are also some reports which indicate that the leaf extracts can act as inhibitors of corrosion of carbon steel in neutral or alkaline environments, however, the number of such reports is relatively less than those observed for acidic media. Some of them are Fouda et al. (2017), Onukwube et al. (2016) and Ayeni et al. (2012).

Based on the literature reports mentioned above, the authors of the present work were interested to study the inhibitory effects of a plant extract which can work in acidic, neutral and alkaline environments. Further, they were curious to study the effect of various environmental factors like temperature, immersion time, etc. on inhibition efficiency of the new natural and environmentfriendly corrosion inhibitor. During the search for the new green inhibitor, the authors came across the Aerva lanata plant.

Aerva lanata, also called mountain knotgrass, is a woody perennial herb belonging to Amaranthaceae family of genus Aerva, native of Asia and Africa. The plant grows wild everywhere in the plains of India. The whole plant, especially the leaves, is edible. It is taken as a vegetable food for both human beings and animals. Different parts of the plant are used as traditional medicine for various diseases. For instance, the juice of crushed Aerva lanata root is used for jaundice therapy. The aqueous extract of Aerva lanata stem was reported to exhibit in vitro antioxidant activity (Gaurav Kumar et al.,2013). To the knowledge of the authors of the present work, no study was reported in literature so far based on Aerva lanata leaves extract as a corrosion inhibitor for any metal/alloy in any environment. Hence, the aqueous extract was considered for its inhibitory effects on carbon steel corrosion in aqueous environment. The main objective of the present study was to investigate the effectiveness of Aerva lanata leaves extract for corrosion inhibition of carbon steel in chloride environment and to study the influence of various factors on inhibition efficiency. Gravimetric studies provide real picture of effectiveness of inhibition by a corrosion inhibitor, while the other methods like electrochemical and surface analytical methods provide information useful for establishing mechanistic aspects of the inhibition. This paper presents the results obtained in gravimetric measurements under different environmental conditions. These results indicated that Aerva lanata leaves extract acts as an effective corrosion inhibitor.

\section{Materials and Methods}

The aim of the present work was to study the efficiency of Aerva lanata leaves extract as an inhibitor for carbon steel. It does not include establishment of mechanistic aspects of the corrosion inhibition process by the extract. Hence, all the studies in the present work were carried out using gravimetric measurements alone which provide realistic data with reference to effectiveness of inhibitor formulations.

Carbon steel specimens of the dimensions $3.5 \mathrm{~cm} \times 1.5 \mathrm{~cm} \times 0.2 \mathrm{~cm}$ and of the following composition were used in the present study: $\mathrm{C}=0.1-0.2 \%, \mathrm{P}=0.04-0.07 \%, \mathrm{~S}=0.03-0.04$ $\%, \mathrm{Mn}=0.3-0.5 \%$, and the rest iron. Before the test, the specimens were finely polished to mirror finish with emery polishing papers, washed with distilled water, degreased with acetone and then dried. For weighing the specimens, a digital top pan electronic balance with $0.01 \mathrm{mg}$ accuracy from Shimadzu (Model AUW-220) was used. 
Aerva lanata leaves extract was prepared as follows. 200 grams of leaves of Aerva lanata were collected and distilled in 2 litres of distilled water for about 2 hours. The resulting aqueous extract was taken as inhibitor stock solution. It was added at different percentages to the control solution. Throughout the study, $200 \mathrm{ppm}$ of $\mathrm{NaCl}$ solution was taken as the control solution. After establishing the required concentration of the extract for effective inhibition, the influence of various factors like $\mathrm{pH}$, immersion period, temperature, aggressiveness of the medium and maintenance dosages was studied.

Corrosion rates (CR) of carbon steel in the absence and presence of extract were calculated in milligrams per square decimeter per day (mdd).

Corrosion rate $(\mathrm{mdd})=\frac{\text { Loss in weight in } \mathrm{mg}}{\text { Surface area of specimen in } \mathrm{dm}^{2} \mathrm{x} \text { Immersion period in days }}$

Corrosion rates were expressed in millimeter per year (mmpy) using the following equation.

Corrosion rate $(\mathrm{mmpy})=($ Corrosion rate in mdd $\mathrm{x} 0.0365) /$ density of carbon steel $(7.8611 \mathrm{~g} / \mathrm{cc})$

Inhibition efficiencies (IE) of the extract were calculated by using the formula, $\mathrm{IE}(\%)=100\left[(\mathrm{CR})_{\mathrm{o}}-(\mathrm{CR})_{\mathrm{I}}\right] /(\mathrm{CR})_{\mathrm{o}}$ where $(\mathrm{CR})_{\mathrm{O}}$ and $(\mathrm{CR})_{\mathrm{I}}$ are the corrosion rates in the absence and presence of inhibitor respectively.

\section{Results and Discussions}

\subsection{Corrosion Inhibition of Carbon Steel Using Aerva Lanata Leaf Extract}

In order to determine the effectiveness of the leaf extract of the plant namely Aerva lanata plant, the preliminary studies were conducted using gravimetric measurements. The extract was added at the concentrations from 1 to $5 \%$ to the control and the carbon steel specimens were immersed for a contact period of 7 days. Based on the loss of weights of the specimens after the immersion period, corrosion rates and inhibition efficiency values were calculated and presented in Table 1. It shows that with increase in concentration of the extract, the inhibition efficiency increases reaching $95.57 \%$ at $5 \%$ of the extract. There are some recent reports showing plant extracts as good corrosion inhibitors in different environments (Chandrabhan Verma et al., 2018; Cookey et al., 2018; Hamdan et al., 2018; Khadom et al., 2018; Muthukrishnan et al., 2017).

The results of the preliminary studies on the leaf extract indicated that the extract can act as an effective corrosion inhibitor for carbon steel. In order to establish the extract as an efficient inhibitor, corrosion inhibition studies were continued by considering the effects of various factors on inhibition efficiency. For this purpose, the parameters considered were $\mathrm{pH}$, longer immersion period, temperature and concentration of chloride. 
Table 1: Corrosion rates of carbon steel and inhibition efficiencies of the extract at different

\begin{tabular}{|l|l|l|l|l|}
\hline S. No. & $\begin{array}{l}{[\mathbf{N a C l}]} \\
(\mathbf{p p m})\end{array}$ & $\begin{array}{l}\text { Extract } \\
(\% \mathbf{v} / \mathbf{v})\end{array}$ & $\begin{array}{l}\text { Corrosion rate } \\
(\mathbf{m m p y})\end{array}$ & Inhibition efficiency (\%) \\
\hline 1 & 200 & 0 & 0.09329 & - \\
\hline 2 & 200 & 1 & 0.07516 & 19.43 \\
\hline 3 & 200 & 2 & 0.05457 & 41.50 \\
\hline 4 & 200 & 3 & 0.03192 & 65.78 \\
\hline 5 & 200 & 4 & 0.01497 & 83.95 \\
\hline 6 & 200 & 5 & 0.00413 & 95.57 \\
\hline
\end{tabular}

\subsection{Effect of $\mathrm{pH}$}

Literature survey indicates that there have been many reports showing plant extracts as effective corrosion inhibitors for carbon steel or other metals in acidic media (Ibisi et al., 2016; Michael et al., 2014; Shanmuga Priya et al., 2015). On the other hand, there are a few reports on such inhibitors exhibiting good inhibition efficiency in neutral/alkaline environments (Ayeni et al., 2012; Fouda et al., 2017; Onukwube et al., 2016).

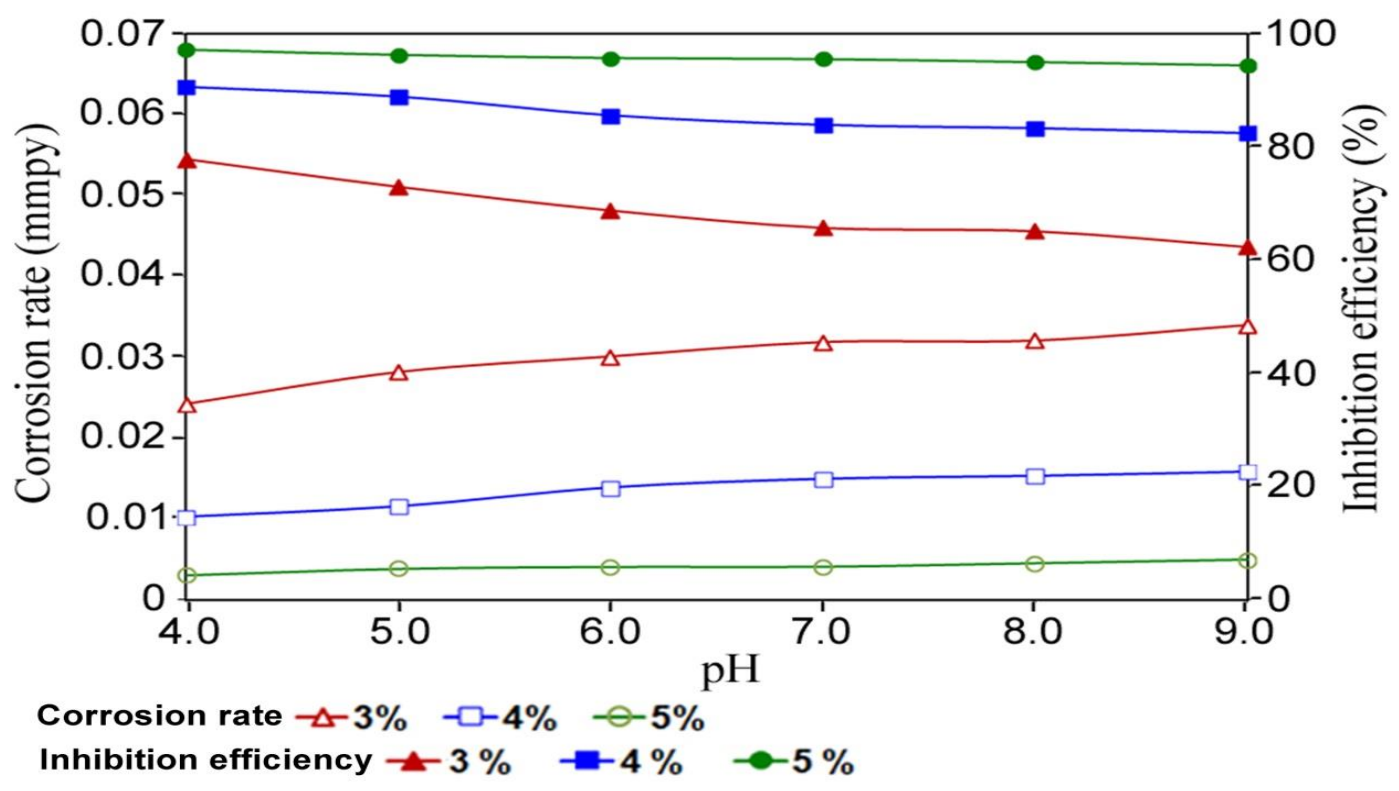

Figure 1: Corrosion rates of carbon steel and inhibition efficiencies of the extract at various concentrations in $200 \mathrm{ppm}$ of $\mathrm{NaCl}$ solution at different $\mathrm{pH}$ values

Hence, the investigator was interested to verify the effectiveness of the inhibitor at different $\mathrm{pH}$ values covering both acidic and basic media. The effect of variation in $\mathrm{pH}$ of $200 \mathrm{ppm}$ of $\mathrm{NaCl}$ solution on inhibition efficiency of the leaf extract at different concentrations is shown in Fig. 1. The figure indicates that the extract is efficient in a wide $\mathrm{pH}$ range from 4.0 to 9.0. An interesting feature observed from the inhibition efficiency values is that at any $\mathrm{pH}$ value, the inhibition efficiency increases with increase in concentration of the extract. Further, at any specific concentration of the inhibitor, inhibition efficiency slightly decreases from $\mathrm{pH}=4.0$ to 9.0. It infers that the extract is more effective in the acidic medium than in alkaline medium. 


\subsection{Effect of Immersion Period}

Although the extract was investigated for its inhibition efficiency initially for a period of 7 days, later the immersion period was increased and the efficiency was tested at three different concentrations, $3 \%, 4 \%$ and $5 \%$ for longer immersion periods up to 60 days. The results are shown in Fig. 2. The figure indicates that up to an immersion period of 30 days, the inhibition efficiency is remained almost same at all the three concentrations. Beyond an immersion period of 30 days, significant decrease in inhibition was observed at the concentrations $3 \%$ and $4 \%$. Although the same trend is observed for the inhibitor at the concentration of $5 \%$, the effect was not much significant. This is evident from the fact that the inhibition efficiency at $5 \%$ concentration is $95.92 \%$ after an immersion time of 10 days and it decreases to $92.41 \%$ even after an immersion period of 60 days.

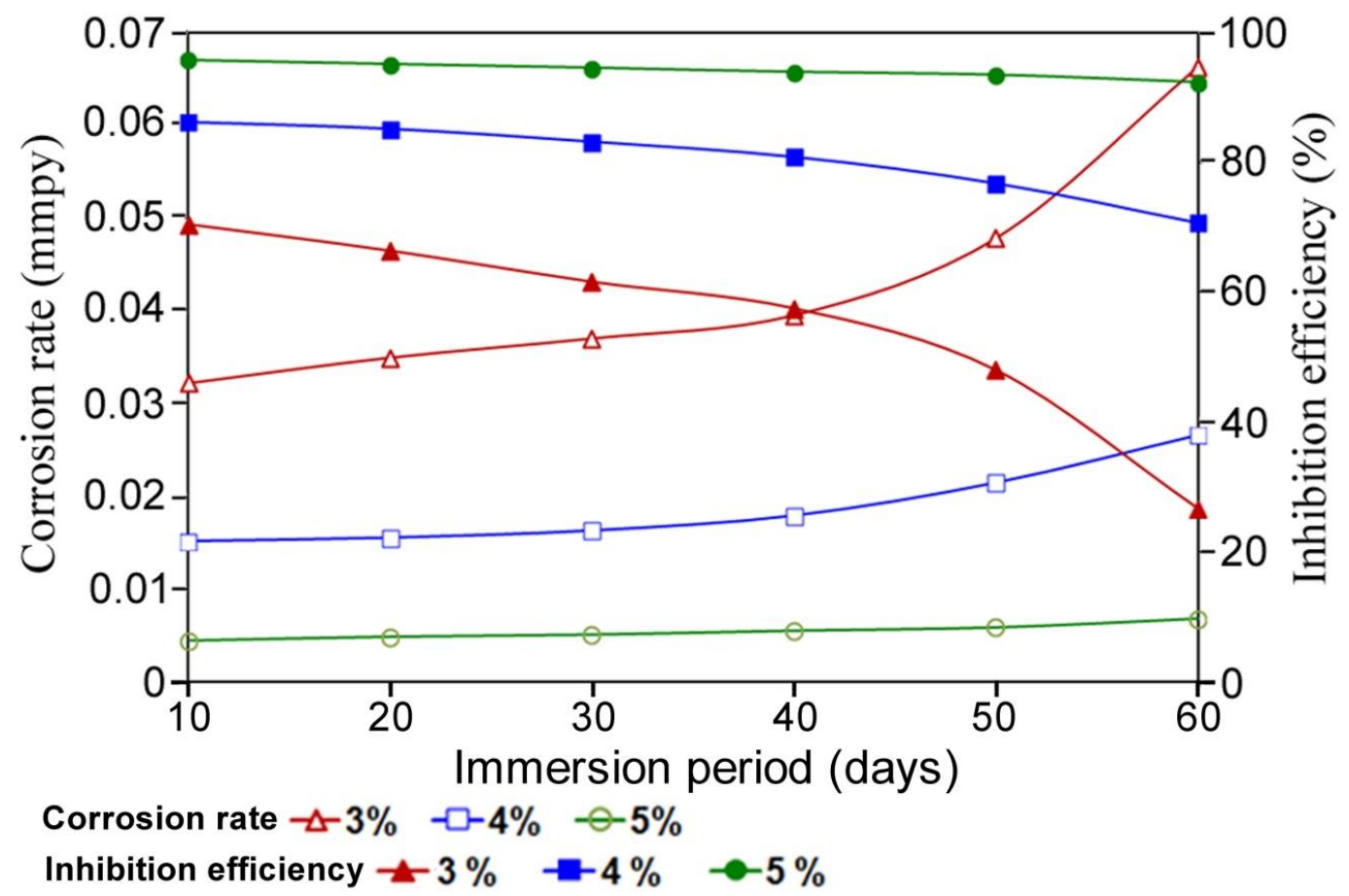

Figure 2: Corrosion rates of carbon steel and inhibition efficiencies of the extract at various concentrations in $200 \mathrm{ppm}$ of $\mathrm{NaCl}$ solution at different immersion periods

The decrease in inhibition efficiency with immersion time can be explained as follows. When a metal surface is immersed in a chloride environment, the chloride ions, due to their high penetration power, attack the surface and cause severe corrosion. But, in presence of an effective inhibitor, the inhibitor molecules get adsorbed on the surface and prevent the attack by the chloride ions. During longer immersion periods, the chloride ions in solution continuously keep on trying to diffuse to the surface. But, until the inhibitor molecules are adherent to the surface, chloride ions fail to attack the surface. During longer immersion times, it is possible that inhibitor molecules present at some areas may fail to get adsorbed to the surface and thus, attack of the chloride ions in those areas becomes fruitful. The results in the present study indicate that the inhibitor at $5 \%$ concentration is effectively protecting the surface from the aggressiveness of the medium even up to 60 days of contact period. 


\subsection{Effect of Temperature}

Temperature is an important environmental factor to be considered in corrosion inhibition studies in view of its significant influence on inhibition efficiency of any corrosion inhibitor. Gravimetric studies were conducted at about $303 \mathrm{~K}$ in order to establish the efficiency of the inhibitor. Later, the studies were conducted at different elevated temperatures up to $333 \mathrm{~K}$. The results of the studies were presented in Figure 3.

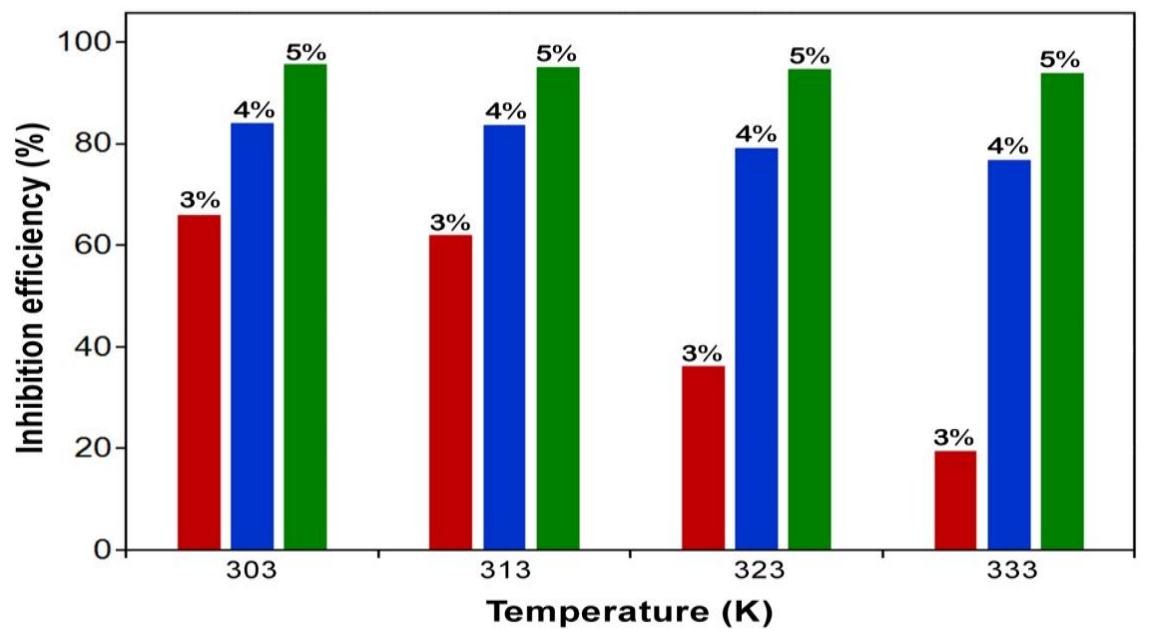

Figure 3: Inhibition efficiency of $3 \%, 4 \%$ and $5 \%$ of the extract in $200 \mathrm{ppm}$ of $\mathrm{NaCl}$ solution at different temperatures

The figure shows that inhibition efficiency of the inhibitor decreases with increase in temperature at all the concentrations of the inhibitor studied. However, the decrease in inhibition efficiency is less at higher concentrations of the inhibitor. At $3 \%$ of the inhibitor, the inhibition efficiency at $303 \mathrm{~K}$ is $65.78 \%$ which is drastically decreased to about $20 \%$ at $333 \mathrm{~K}$. The decrease in inhibition efficiency with increase in temperature can be attributed to desorption of inhibitor molecules at some areas of the metal surface. With $5 \%$ of the inhibitor, the inhibition efficiency is $94 \%$ even at $333 \mathrm{~K}$. Hence, from the results it can be concluded that the inhibitor is effective at higher temperatures also.

\subsection{Effect of Aggressiveness of Medium}

It is well-known that the effectiveness of a corrosion inhibitor always depends on the nature and aggressiveness of the corrosive medium. Many researchers working on corrosion in neutral environments prefer choosing $\mathrm{NaCl}$ as the medium in view of high aggressiveness of chloride ions. With increase in concentration of chloride ions, the aggressiveness of the medium increases. The inhibitors that efficiently work at low chloride media generally fail at higher concentrations of chloride. This is due to the fact that at higher concentrations, chloride ions can easily compete with the inhibitor molecules in reaching the metal surface. Secondly, chloride ions at higher concentrations can penetrate the protective film produced by the inhibitor molecules and can easily attack the surface. In order to verify the effectiveness of the extract at higher concentrations of chloride ions, studies were conducted at different concentrations of $\mathrm{NaCl}$ up to $350 \mathrm{ppm}$. The results obtained are shown in Figure 4. 


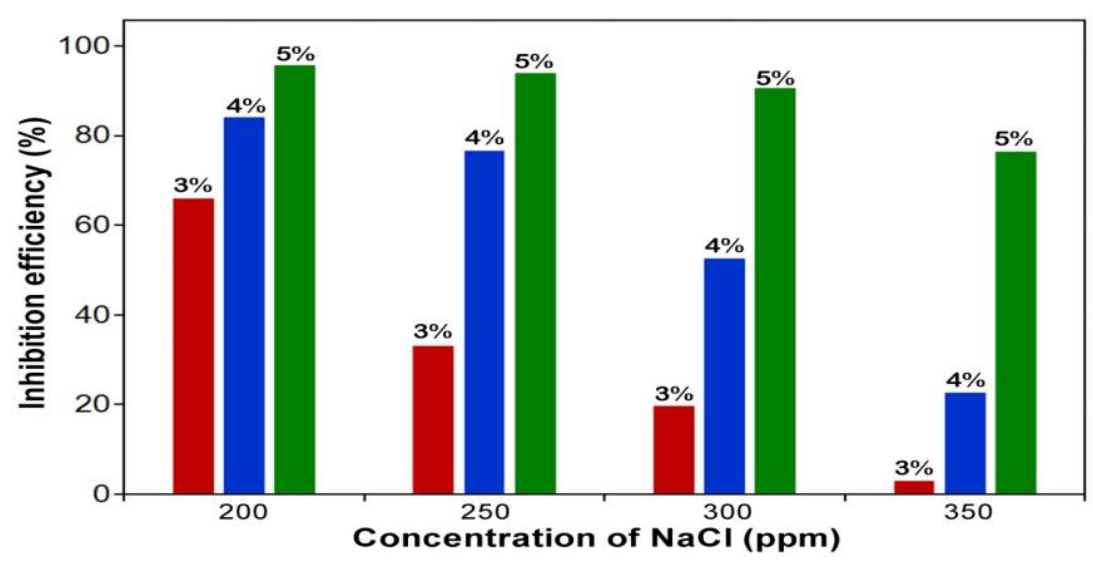

Figure 4: Inhibition efficiency of $3 \%, 4 \%$ and $5 \%$ of the extract in $200 \mathrm{ppm}$ to $350 \mathrm{ppm}$ of $\mathrm{NaCl}$ solution

As expected, inhibition efficiency is decreased with increase in concentration of $\mathrm{NaCl}$ at all the concentrations of inhibitor studied. The figure shows that at higher concentrations of $\mathrm{NaCl}$, the inhibitor is not effective at $3 \%$ and $4 \%$. However, at $5 \%$ of the inhibitor concentration, the inhibition efficiency is maintained above $90 \%$ in $300 \mathrm{ppm} \mathrm{NaCl}$ solution. But, when the aggressiveness was further increased to $350 \mathrm{ppm}$ of $\mathrm{NaCl}$, the inhibitor could not be effective, providing the inhibition efficiency of only $76 \%$. It indicates that the extract at $5 \%$ concentration is able to provide protection from corrosion in $\mathrm{NaCl}$ medium up to the concentration of $300 \mathrm{ppm}$. It may be expected that the extract can be effective for more aggressive media provided the concentration of the inhibitor is also increased.

\subsection{Determination of Maintenance Dosage}

The results of gravimetric studies carried out in order to determine the minimum concentration of the inhibitor for maintenance of the good inhibition efficiency are shown in Table 2 . The results indicate that only $2 \%$ of the extract dosage is enough to maintain the inhibition efficiency greater than $90 \%$.

Table 2: Results of gravimetric studies of the inhibitor for maintenance of inhibition

\begin{tabular}{|l|l|l|l|}
\hline $\begin{array}{l}\text { S. } \\
\text { No. }\end{array}$ & $\begin{array}{l}\text { Maintenance dosage of the inhibitor } \\
(\boldsymbol{\%})\end{array}$ & $\begin{array}{l}\text { Corrosion } \\
\text { rate } \\
(\mathbf{m m p y})\end{array}$ & $\begin{array}{l}\text { Inhibition efficiency } \\
(\boldsymbol{\%})\end{array}$ \\
\hline 1 & 0 & 0.07298 & 21.77 \\
2 & 1 & 0.04026 & 56.84 \\
3 & 2 & 0.00918 & 90.16 \\
4 & 3 & 0.00428 & 95.41 \\
5 & 4 & 0.00431 & 95.38 \\
6 & 5 & 0.00425 & 95.44 \\
\hline
\end{tabular}

\section{Conclusions and Recommendations}

The extract of the Aerva lanata plant leaves acts as an effective corrosion inhibitor for carbon steel in aqueous media containing chloride ions. The optimum concentration of the extract required for 
an effective inhibition is $5 \%(\mathrm{v} / \mathrm{v})$. Further, the extract shows good inhibition in the $\mathrm{pH}$ range from 4.0 to 9.0 . The inhibitor is efficient at elevated temperatures up to $333 \mathrm{~K}$. The extract at $5 \%$ concentration protects the metal from corrosion in the environment containing $300 \mathrm{ppm}$ of $\mathrm{NaCl}$. It is expected that the inhibitor can work in still more aggressive environments at concentrations greater than $5 \%$. The required minimum dosage of the extract for maintenance of the protective nature was found to be only $2 \%$. The protective nature of the extract in $200 \mathrm{ppm}$ of $\mathrm{NaCl}$ solution was maintained even up to 60 days of immersion period. Thus, the extract is an effective ' $g r e e n$ ' inhibitor for carbon steel in aqueous media, as inferred by the results of gravimetric measurements. The establishment of mechanism of corrosion inhibition using electrochemical studies is under the process.

\section{Acknowledgements}

One of the authors, Mr. V. Rajesh is grateful to the Management and Principal of V. R. Siddhartha Engineering College for their encouragement and support in carrying out research activities. The authors are thankful Dr. S. Srinivasa Rao, Associate Professor, Department of Chemistry, V. R. Siddhartha Engineering College, Vijayawada, for his help in the interpretation of results.

\section{References}

[1] Akoma Chigozie S., Osarolube Eziaku, And Abumere O.E. (2018). "Electrochemical Studies for Corrosion Inhibition of Mild Steel by Chrysophyllum Albidum Extract." International Journal of Research - Granthaalayah, 6(1), 415-420. Https://Doi.Org/10.5281/Zenodo.1168938.

[2] Appa Rao B.V., Venkateswara Rao M., Srinivasa Rao S., And Sreedhar, B. (2010). "Tungstate as A Synergist to Phosphonate Based Formulation for Corrosion Control of Carbon Steel in Nearly Neutral Aqueous Environment.” Journal of Chemical Sciences, 122(4), 639-649. Https://Www.Ias.Ac.In/Article/Fulltext/Jcsc/122/04/0639-0649.

[3] Appa Rao B.V., Venkateswara Rao M., Srinivasa Rao S., And Sreedhar B. (2011). "Synergistic Effect Of N, N-Bis (Phosphonomethyl) Glycine and Zinc Ions in Corrosion Control Of Carbon Steel In Cooling Water Systems.” Chemical Engineering Communications, 198(12), 1505-1529. Https://Doi.Org/10.1080/00986445.2010.525200.

[4] Ayeni F.A., Madugu I.A., Sukop P., Ihom A.P., Alabi O.O., Okara R., And Abdulwahab M. (2012). "Effect of Aqueous Extracts of Bitter Leaf Powder on The Corrosion Inhibition of Al-Si Alloy In 0.5 M Caustic Soda Solution." Journal of Minerals and Materials Characterization and Engineering, 11(7), 667-670. Https://Doi.Org/10.4236/Jmmce.2012.117050.

[5] Chandrabhan Verma, Quraishi M. A., Eno E. Ebenso, And Indra Bahadur. (2018). "A Green and Sustainable Approach for Mild Steel Acidic Corrosion Inhibition Using Leaves Extract: Experimental and Dft Studies." Journal of Bio-Tribo-Corrosion, 4(3), 33. Https://Doi.Org/10.1007/S40735-018-0150-3.

[6] Cookey G.A., Tambari B.L., And Iboroma D.S. (2018). "Evaluation of The Corrosion Inhibition Potentials of Green-Tip Forest Lily (Clivia Nobilis) Leaves Extract on Mild Steel in Acid Media." Journal of Applied Sciences and Environmental Management, 22(1), 90-94. Https://Dx.Doi.Org/10.4314/Jasem.V22i1.16.

[7] Fouda A.S., Emam A., Refat R., And Nageeb M. (2017). "Cascabela Thevetia Plant Extract as Corrosion Inhibitor for Carbon Steel in Polluted Sodium Chloride Solution.” Journal of Analytical and Pharmaceutical Research, 6(1), 00168. Https://Doi.Org/10.15406/Japlr.2017.06.00168.

[8] Gaurav Kumar, Loganathan Karthik, And Kokati Vankata Bhaskara Rao. (2013). "Phytochemical Composition And In Vitro Antioxidant Activity of Aqueous Extract of Aerva Lanata (L.) Juss. Ex Schult. Stem (Amaranthaceae).” Asian Pacific Journal of Tropical Medicine, 6(3), 180-187. 
Https://Doi.Org/10.1016/S1995-7645(13)60020-6.

[9] Hamdan A.B., Suryanto, And Haider F.I. (2018). "Study on Tea Leaves Extract as Green Corrosion Inhibitor of Mild Steel in Hydrochloric Acid Solution.” Iop Conference Series: Materials Science and Engineering, 290, 012086. Https://Doi.Org/10.1088/1757-899x/290/1/012086.

[10] Ibisi N.E., And Ufodiama Ch. (2016). "Acanthus Montanus Extract as Sustainable and EcoFriendly Corrosion Inhibitor of Mild Steel in Acidic Medium.” International Journal of Research in Chemistry and Environment, 6(2), 23-27.

Https://Www.Ijrce.Org/Abstract.Php?Article_Id=739.

[11] Khadom A.A., Abd A.N., And Ahmed N.A. (2018). "Xanthium Strumarium Leaves Extracts as A Friendly Corrosion Inhibitor of Low Carbon Steel in Hydrochloric Acid: Kinetics and Mathematical Studies.” South African Journal of Chemical Engineering, 25, 13-21. Https://Doi.Org/10.1016/J.Sajce.2017.11.002.

[12] Michael N.C., And Olubunmi J.A. (2014). "The Corrosion Inhibition of Mild Steel in Sulphuric Acid Solution by Flavonoid (Catechin) Separated from Nypa Fruticans Wurmb Leaves Extract." Science Journal of Chemistry, 2(4), 27-32. Https://Doi.Org/10.11648/J.Sjc.20140204.11.

[13] Muthukrishnan P., Jeyaprabha B., And Prakash P. (2017). "Adsorption and Corrosion Inhibiting Behavior of Lannea Coromandelica Leaf Extract on Mid Steel Corrosion." Arabian Journal of Chemistry, 10(Supplement 2), S2343-S2354. Https://Doi.Org/10.1016/J.Arabjc.2013.08.011.

[14] Onukwube N.D., Awomukwu D.A., And Brown N. (2016). "Inhibition of Corrosion of Mild Steel in Alkaline Medium by Ethanol Extract of Pterocarpus Soyauxii Taub Leaves." Ewemen Journal of Analytical \& Environmental Chemistry, 2(1), 38-44. Https://Ewemen.Com/2016/01.

[15] Sarada Kalyani D., Srinivasa Rao S., Sarath Babu M., Appa Rao B.V., And Sreedhar B. (2015). "Electrochemical and Surface Analytical Studies of Carbon Steel Protected from Corrosion in A Low-Chloride Environment Containing A Phosphonate-Based Inhibitor." Research on Chemical Intermediates, 41(8), 5007-5032. Https://Doi.Org/10.1007/S11164-014-1584-Y.

[16] Sarada Kalyani D., Srinivasa Rao S., Chaitanya Kumar K., Roopas Kiran S., Sreedhar B., And Appa Rao B.V. (2017). "Evaluation of Surface/Solution Interface on Carbon Steel in Contact with A Phosphonate-Based Ternary Corrosion Inhibitor System.” Transactions of The Indian Institute of Metals, 70(10), 2497-2508. Https://Doi.Org/10.1007/S12666-017-1112-Z.

[17] Shanmuga Priya K., And Vasudha V.G. (2015). “Acid Extract of Polyalthia Longifolia As A Green Corrosion Inhibitor for Mild Steel in H2so4 Solution.” Iosr Journal of Applied Chemistry, 8(2) (Ver.Ii), 10-16.

Http://Www.Iosrjournals.Org/Iosr-Jac/Papers/Vol8-Issue2/Version-2/C08221016.Pdf.

[18] Srinivasa Rao S., Appa Rao B.V., Roopas Kiran S., And Sreedhar B. (2014). "Lactobionic Acid as A New Synergist in Combination with Phosphonate-Zn (Ii) System For Corrosion Inhibition Of Carbon Steel.” Journal of Materials Science and Technology, 30(1), 77-89. Https://Doi.Org/10.1016/J.Jmst.2013.10.003.

\footnotetext{
*Corresponding author.

E-mail address: rajesh.enviros@ gmail.com
} 